Fecha de recepción: febrero 2019 Fecha de aceptación: julio 2019 Versión final: noviembre 2020

\section{Relaciones y grados de dependencia entre la música y la imagen en los videojuegos: Aproximación a su análisis formal desde la jugabilidad}

Resumen: La generación de un vocabulario específico para el análisis de los videojuegos y el game design es una dificultad de la que tampoco escapa el análisis de la relación imagen-música dentro de ellos. Los conceptos extraídos del cine, del diseño gráfico, o de otros medios lineales serían insuficientes para afrontar esto; la interactividad y no linealidad del medio son tanto su principal dificultad metodológica como sus características distintivas. En este artículo intentaremos vincular la imagen y música y sus maneras de comunicarse entre sí y con el jugador, desde la jugabilidad misma.

Palabras clave: imagen - música - jugabilidad - game design - adaptabilidad - modularidad

[Resúmenes en inglés y portugués en las páginas 72 - 73]

${ }^{(*)}$ Estudiante de la Licenciatura en Música con Orientación en Composición del Instituto Superior de Música de la Universidad Nacional del Litoral, en donde es adscripta en investigación desde el 2017 en el proyecto CAI+D "Movimiento, cuerpo y sonido en escena". Fue artista gráfica y animadora en Killabunnies y en otros proyectos de videojuegos independientes desde el 2015. Además, produce y dirige Poligonía, agrupación coral dedicada exclusivamente a la música de videojuegos.

\title{
Introducción
}

Necesitamos una manera de analizar [video]juegos, intentar entenderlos, y entender qué funciona y qué los hace interesantes. Necesitamos un lenguaje crítico. $Y$, ya que esta es básicamente una forma nueva, a pesar de su tremendo crecimiento y alucinante diversidad, necesitamos inventar uno. (Greg Costikyan - 1994, p. 9)

En 1994 Greg Costikyan escribía un ensayo titulado "No tengo palabras y debo diseñar". La cita que abre este artículo, extraída de ese mismo texto, da cuenta de una tendencia a la necesidad de formalizar el análisis de los videojuegos. Al ser un medio que ha crecido mucho en muy poco tiempo (Glancey, 1996, p. 6), nos encontramos con una cantidad enorme de material y de visiones, difíciles de poner en palabras de manera formalizada o analítica. 
Anna Anthropy, retomando las problemáticas establecidas por Costikyan, considera:

Muchos diseñadores, al faltarles el vocabulario con el cual discutir, analizar y criticar el game design, operan en gran parte por intuición e instinto. Y hay mucho que le debemos a la intuición y el instinto: muchas decisiones radicales son hechas por instinto y luego comprendidas solo en retrospectiva. Pero ¿qué pasa si un diseñador está trabajando en equipo? ¿Si alguien más está dibujando los personajes que aparecerán en el juego? ¿Qué necesitan transmitir, y qué necesita decirles el diseñador? ¿Qué pasa si el diseñador está trabajando con otro diseñador? ¿Cómo se comunicarán ambos sobre las necesidades y la dirección del juego?". (Anthropy y Clark, 2014, p. 6) ${ }^{1}$

¿Por qué Anthropy se ve en la necesidad de reflexionar nuevamente sobre esto, veinte años después que Costikyan? También cavilan sobre esto Hunicke, LeBlanc, y Zubek, quienes en 2004 plantearon como posibilidad para el análisis formal de los videojuegos el marco de referencia MDA (Mechanics, Dynamics and Aesthetics - Mecánicas, Dinámicas y Estética). Éste "intenta cerrar la brecha entre game design y desarrollo, crítica de juegos, e investigación técnica" (Hunicke et al., 2004, p. 1). Tomando en cuenta esto y que Thompson y Ouellette (2013, p. 19) aluden al ensayo de Costikyan bajo las mismas tribulaciones, la respuesta parece ser que aún no se ha logrado esta generación de un vocabulario específico. El análisis de la relación imagen-música en videojuegos tampoco escapa a estas dificultades, que difícilmente puedan abordarse sin un enfoque multidisciplinario. Marks y Sweet basan sus ensayos sobre la composición para videojuegos en los análisis y vocabulario propios del cine, medio con el que se suele relacionar fuertemente a los videojuegos (Marks, 2009, p. xix; Sweet, 2015, p. 17)². Es así como se rescatan los conceptos de música diegética y extradiegética: la música y sonidos que se originan en el mundo ficcional que nos propone el videojuego y los que, por el contrario, no tienen ninguna conexión directa con ninguna fuente visible dentro de él (Jørgensen, On transdiegetic sounds..., 2007, p. 106). Así, las piezas que suenan como música de fondo no son escuchadas por los personajes del juego, sino que sirven para intensificar los sentimientos del jugador. Ahora bien, ¿cómo diferenciamos la música en los juegos de la música en el cine?

Si comenzamos nuestra investigación desde el paradigma de la composición para ficción lineal, podemos argumentar que se diferencia por lo menos en un punto: la interactividad del medio. Costikyan sostiene que es natural relacionar los videojuegos con la producción de películas, ya que todo lo que se ve a primera vista al observarlos es movimiento en una pantalla. Sin embargo, es importante reconocer que el diseño gráfico o el diseño de medios en general no es el diseño de videojuegos. Estaríamos, si no, hablando únicamente de entretenimiento lineal (Costikyan, 1994, p. 27). Ya que el jugador va a ser quien defina el largo del juego (Sweet, 2015, p. 37), también es quien define cómo sonará la música finalmente -en cuanto a repeticiones, superposiciones de módulos ${ }^{3}$, etc.-, para él y su experiencia dentro del juego. Por lo tanto, la manera de hacer música para videojuegos demanda que el compositor trabaje al mismo tiempo en su música y en cómo será percibida su música. 
Por otro lado, Jørgensen cuestiona la utilización estricta de únicamente los conceptos de música diegética y extradiegética para los videojuegos (On transdiegetic sounds..., 2007, p. 106), ya que no solo no es la única manera de catalogar la música dentro del cine, sino que para los videojuegos los límites entre el mundo ficcional, el del jugador, y el espacio extraficcional (ibíd., 2007, p. 108), son maleables y flexibles (ibíd., 2007, p. 113).

Continuando con algunos conceptos presentes en su trabajo (Jørgensen, 'What are Those Grunts..., 2007, p. 51), basaremos el análisis teórico considerando los medios interactivos no lineales.

Al mismo tiempo, nos sería muy difícil abordar la temática de los videojuegos sin mencionar la imagen. Andrew High, columnista en Gamasutra, supone la imposibilidad de analizar la música si no es en función de la imagen y de manera cinematográfica, ya que este medio apunta directamente sobre ella (High, 2012). Pondremos en duda esta afirmación en el marco del presente artículo, ya que desde nuestro punto de vista el medio del videojuego es esencialmente diferente al cine.

Esa particularidad es la relación entre la música y la imagen desde el punto de vista de la jugabilidad, y ese es el enfoque que le daremos a este escrito. (Jørgensen, 'What are Those Grunts..., 2007)

Buscaremos, entonces, con el presente trabajo, delimitar un marco teórico pertinente con el cual abordar subsiguientes análisis, teniendo en cuenta la transversalidad e integración de áreas dentro de los videojuegos, con definiciones pertinentes a estos sistemas y conceptos estéticos correspondientes. Analizaremos ciertos ejemplos musicales seleccionados, en relación con la imagen, desde el punto de vista de la integración al medio y la jugabilidad. Nos preguntaremos cómo se juega con la música, qué comunica esta sobre el juego, y qué posible retroalimentación hay entre la música y la imagen como disparadores del análisis. También indagaremos sobre las maneras en las que la música, mediante elementos no verbales, comunica al jugador necesidades de la jugabilidad o exigencias de input para continuar con el juego.

Con estos lineamientos, nos aproximaremos al análisis formal y a la generación de un vocabulario más pertinente al área de los videojuegos. Así, comenzaremos refiriéndonos a la herencia de otros medios, para luego buscar independizar los análisis de los problemas ajenos a los de los videojuegos.

\section{El juego entre la música y la imagen}

\subsection{Definiciones clave}

Continuando con las problemáticas que plantean Costikyan (1992) y Anthropy y Clark (2014), para afrontar correctamente este trabajo será necesario aproximarnos a delimitar y precisar algunas definiciones que serán utilizadas a lo largo de él.

Podemos comenzar desde la pregunta fundamental ¿qué es un videojuego? Una definición podría ser "un juego que jugamos gracias a un aparato audiovisual [...]" (Esposito, 2005, p. 2) ${ }^{4}$. Si bien simple, incluye los términos clave desde los que se desprenden los conceptos que utilizaremos a lo largo de todo el siguiente texto: jugabilidad y aparato audiovisual. 
Quizás lo primero que nos venga a la mente cuando hablamos de videojuegos son las imágenes antes que las músicas. Las imágenes visuales son usadas tal como las vemos en la comunicación visual del día a día: para guiar, dirigir y comunicar. El elemento visual sirve para guiar la acción de un jugador y comunicarle pasos a seguir o posibilidades a tener en cuenta, incluyendo desde los personajes y la representación del mundo del juego hasta su interfaz y menús.

En su libro Visual Methodologies, Gillian Rose (2001, p. 136) construye el concepto de discurso visual desde la concepción de discurso de Foucault -"grupos de declaraciones que estructuran la manera en la que se piensa una cosa, y la manera en la que actuamos en base a esa forma de pensar; es decir, un conocimiento particular sobre el mundo que da forma a cómo entendemos el mundo y cómo se hacen las cosas en él." Entiende también el arte como discurso en que es una forma especializada de conocimiento. En esta concatenación de imágenes en pos de la comunicación, se puede inferir también la intertextualidad, "la manera en la que los significados de cualquier imagen o texto discursivo no dependen únicamente de ese único texto o imagen, sino también en los significados que otras imágenes y textos tienen." (ibíd., p. 137)

En este discurso articulado, en constante intercambio entre sus partes, es donde las imágenes visuales y la música se encuentran, dentro del medio particular de los videojuegos. Natkin (2010, p. 166) habla de los juegos como medio refiriéndose a ciclos de tensión/ resolución, "en donde el jugador siente la resolución de un ciclo como alguna consecuencia de sus decisiones". ${ }^{6}$ El mecanismo por el cual se desarrollan estos ciclos es el gameplay, o jugabilidad, en español. ${ }^{7}$ Es, según González Sánchez, Padilla Zea y Gutiérrez Vela (2009, p. 67), "El conjunto de propiedades que describen la experiencia del jugador ante un sistema de juego determinado, cuyo principal objetivo es divertir y entretener de forma satisfactoria y creíble [...]." La jugabilidad, entonces, estará atravesada por lo sonoro y lo visual, ya que son los medios por los cuales el jugador y el mundo del juego se comunican. Cabe notar también que la música para juegos se emparenta, por lo menos a primera vista, con la música de cine y otros medios audiovisuales en la utilización de leitmotifs, temas o ideas musicales "cuyo propósito es representar o simbolizar una persona, objeto, lugar, idea, estado, fuerza sobrenatural o cualquier otro ingrediente en una obra dramática", según The New Grove Dictionary of Music and Musicians. Los leitmotifs también aparecen como pistas visuales o se reflejan en la imagen.

Indefectiblemente debemos retomar algunas definiciones del mundo del cine que nos son útiles; particularmente, las de la música diegética y extradiegética o no diegética. La primera es la música que el personaje escucharía en el mundo que nos plantea el juego; los jugadores ven la fuente directa de la música o el sonido. La música no diegética es la que existe puramente como fondo imaginario de una escena o situación dentro del juego. (Sweet, 2015, pp. 58-60)

También veremos la recurrencia de palabras en inglés para referirse a conceptos específicos de los sistemas computacionales, como input, que se refiere a la entrada de datos de cualquier tipo por parte del usuario, y feedback, "retroalimentación", que es la información que da el sistema al usuario para hacerle saber que se efectuó una interacción. (Schell, 2008, p. 148) Un término que veremos frecuentemente a lo largo del presente artículo es 
gameplay. Ya Costikyan reflexiona sobre la dificultad de describirlo formalmente (1994, p. 9); comenzaremos a definirlo con lo escrito por Rollings y Adams: "[...] el gameplay no es una entidad singular. Es una combinación de varios elementos, una sinergia que emerge de la inclusión de ciertos factores. [...] El gameplay emerge de la interacción entre esos elementos" (2003, p. 237). Será importante de aquí en adelante la problemática planteada por lo amplio y maleable de este concepto.

Los videojuegos se basan en recursos finitos para lograr una cantidad indefinida de tiempo de juego, normalmente mucho mayor a la cantidad de material producido (ya sea musicalmente, desde la imagen, o en jugabilidad). Por lo tanto, y al contrario del cine, cuentan también con la posibilidad de la adaptabilidad -la posibilidad de, a través de la retroalimentación constante y activa, reacomodar y reutilizar los escasos recursos que conforman el juego (Sweet, 2015, p. 17). Así, una animación del estado 'caminar' se repite tantas veces como pasos desee hacer el jugador en una escena, y la música perteneciente a ella se repetirá -utilizando diferentes recursos para evitar el cansancio- (Marks, 2009, p. 12), tantas veces como el tiempo durante el que el jugador permanezca en ella.

Podemos entonces, mediante las definiciones anteriores, establecer elementos para el análisis dentro de unos márgenes definidos, para así responder -por lo menos dentro de nuestro marco- a las necesidades comunicacionales-analíticas dispuestas por Anthropy. Así es como nos preguntamos ¿pueden estos 'bloques' formales aplicarse para el análisis de la estructura de los videojuegos? En la siguiente sección, seguiremos explorando las relaciones entre la música y la imagen, y luego intentaremos introducir a esta estructura las definiciones ya exploradas, con el objetivo de lograr una aproximación estética a los elementos formales de los videojuegos y esclarecer la relación bilateral entre ellos.

\subsection{Música e imagen}

El sonido es un canal muy diferente al video. Puede apoyar la información visual, oponerse a ella, clarificarla o confundirla.

Anna Anthropy. (Anthropy y Clark., 2014, p. 96)

Desde las definiciones previamente establecidas, podríamos preguntarnos ya no solo por el rol de la música en los videojuegos, o de la imagen en ellos, sino por sus interrelaciones. Pueden surgir nuevamente comparaciones con el cine, pero necesariamente tendremos que ir más allá de las categorizaciones tradicionales que aplican a éste, para dar cuenta no solo de lo audiovisual, sino de lo interactivo y lo no lineal propio de los videojuegos. En esta línea de pensamiento se inscriben Berndt y Hartmann, quienes retoman el manifiesto de Eisenstein, Pudovkin y Alexandrov 9 . Distinguen dos categorías de las relaciones del sonido hacia la imagen: paralelismo (música que sigue y refleja el contenido visual) y contrapunto (música que contradice la escena). (Berndt y Hartmann, 2008, p. 7) Nuevamente estos autores ubican su punto de partida en el cine; sin embargo, en los próximos párrafos demostraremos por qué nos hemos alejado de este paradigma.

Anthropy sostiene lo siguiente: 
Los juegos digitales, funcionando en pantallas, respirando a través de parlantes, son capaces de presentar información visual y auditiva al jugador. Imágenes, animación, sonidos, música. Podemos usar esos canales para comunicar las reglas de nuestros juegos, para enfatizar y resaltar las interacciones importantes. (Anthropy y Clark., 2014, p. 80)

La música y la imagen, entonces, nos permiten indicar de modo no verbal maneras de jugar y elementos del gameplay.

En la imagen, podríamos pensar en los motivos visuales, los cuales les permiten a los desarrolladores crear un índice implícito de reglas del juego que el jugador comprende. Si el diseñador utiliza espinas para indicar algo peligroso, la próxima vez que el jugador vea cualquier objeto que utilice el mismo motivo, lo asociará con algo que no debe tocar -es decir, con una acción específica que debe o no tomar. (ibíd., p. 103) Lo mismo sucede con el diseño de personajes y la animación. (ibíd., pp. 81-86)

Una categorización del audio en videojuegos de la que nos haremos eco es el sonido como énfasis y el sonido como textura, nuevamente propuestas por Anthropy. El sonido puede hacer hincapié sobre acciones que ha tomado el jugador, a modo de recompensa o castigo, o bien como indicación sonora de elementos jugables. Pero, también, puede funcionar como un estrato, una capa textural que suena constantemente, que puede ser agregada o quitada para cambiar la relación inmediata del jugador con el mundo. (ibíd., p. 90)

Es importante agregar a estas definiciones propuestas por Anthropy lo que establece Jørgensen en su artículo Left in the Dark: "[...] los canales auditivo y visual son las únicas maneras en las que el sistema se puede comunicar con el jugador” (Jørgensen, 2008, p. 164). Es decir, no solo pueden describir sus reglas, sino que los videojuegos, en la mayor parte de los casos, no tienen otra forma de hacerlo; la música y la imagen no son accesorias ni podrían ser menos importantes que las mecánicas de juego. ¿Qué es una serie de instrucciones (Anthropy y Clark., 2014, p. 109) si no pueden comunicar que existen ni ser ejecutadas?

\subsection{Jugando con la música: adaptabilidad}

La modularidad que permite el medio de los videojuegos será un factor clave en los análisis; está entendida como 'bloques' de información -sea musical, visual o de comportamiento del sistema del juego- que pueden ser repetidos o reacomodados según el sistema requiera, o según el input del jugador. Esta modularidad se ve presente en todos los aspectos: bloques del juego se repiten organizados de distinta manera para crear experiencias distintas pero reconocibles y rápidamente aprehensibles (Agosta, 2018)10. La información no es nueva sino que se construye en relación a lo presentado anteriormente durante el juego.

Un bloque mínimo adaptativo es tan pequeño como la posibilidad de repetición lo permita. No podríamos decir que un píxel es un bloque adaptativo porque, más allá de las razones técnicas, no distinguiríamos dos píxeles iguales como la repetición uno del otro -tal como ocurriría si comparáramos dos negras sin tomar en cuenta nada más del resto de su sistema. 
También podemos generar un paralelismo entre la adaptabilidad y experimentaciones en obras del siglo XX con la modularidad y la posibilidad de darle al intérprete (en nuestro caso, al jugador) entidad en el proceso creativo de la obra. El sistema está planteado previo a que el intérprete tome la obra, pero la obra sólo ocurre cuando el intérprete la organiza y la hace sonar, proceso enteramente personal dentro de los límites del sistema propuesto por el compositor (Eco, 1962, pp. 32-34). En este sentido, esta injerencia en la creación del todo también es dada a los jugadores, con mayor o menor grado de libertad.

\subsection{Aproximación a las categorías de análisis. Conocimientos interdisciplinares y la importancia de la experiencia del usuario}

En cualquier conversación, necesitamos a alguien con quién hablar. Sin un jugador, un juego es solo un conjunto de instrucciones, así sean ejecutadas por una computadora o seres humanos que aprenden qué cartas tomar en su turno. Un juego sin jugar es como una partitura: se puede ver su potencial e imaginar cómo sonaría. Se puede percibir desde la notación que es compleja y quizás entrever su naturaleza [...]. (Naomi Clark - Anthropy y Clark, 2014, p. 109)

Coincidiendo con diversos autores y continuando con lo planteado en la sección 1.2, buscamos demostrar la estrecha relación entre música e imagen, desde la medida de la jugabilidad, en los videojuegos. Algunos autores han ido más lejos y aseveran que, además de lo visual y lo auditivo, también lo narrativo, las mecánicas de juego y la historia son parte de un todo inseparable. (Agosta, ver anexo) ¿Qué tan útil es, entonces, analizar la armonía de una pieza si no tenemos en cuenta qué función cumple respecto a la imagen o al gameplay? Para este trabajo se vuelve necesario proponer categorías nuevas - no tradicionales- de análisis que respondan a esta intersección de áreas, a las obras multimedia, no lineales e interactivas. Puede partirse del análisis de obras multimedia y luego ampliar esos análisis para incluir al receptor como partícipe activo, y, así, al gameplay.

Ya hemos explicado el concepto básico de adaptabilidad anteriormente. Si bien solo es mencionado en fuentes sobre música para videojuegos (Sweet, 2015; Marks, 2009), es interesante retomarlo para aplicarlo nuevamente al resto de los factores que conforman un videojuego. Hacemos la salvedad de que, al hablar sobre game design, la adaptabilidad del medio se presupone, ya que para cumplir con su aspecto básico de videojuego debe ser interactivo y responsivo (Agosta, 2018). La música para videojuegos no necesitó ser adaptativa originalmente, más allá de poder transicionar entre su fin y nuevo comienzo en bucle (Youngdahl, 2010, p. 46); sin embargo, hoy podríamos decir que para responder a las demandas del medio y del mercado, y acompañando los procesos que ya existen visualmente y desde la programación, la adaptabilidad se ha vuelto la regla (Berndt y Hartmann, 2008, p. 10).

Es así como podemos encontrar una relación con conceptos tradicionales del análisis formal musical: los videojuegos se pueden pensar como sistemas de varias partes, en donde se alternan la repetición, la introducción de nuevo material y las variaciones del mismo (Agosta, 2018). Analizándolos de esta manera, podríamos ver cómo responden ante el 
juego las distintas secciones formales de la música y la imagen, y cómo se suceden entre sí. La decisión de utilizar elementos del análisis formal tradicional responde a la modularidad de los juegos: si bien el "esquema formal" de los juegos no está definido -será el intérprete/jugador el que lo defina activamente-, sí lo están sus partes internamente y estas son, normalmente, imposibles de modificar para el jugador.

Gonzalo Agosta, principal game designer de Killabunnies nos plantea un punto de vista desde la experiencia del jugador. Así es como nos encontramos en la necesidad de analizar la música de los videojuegos no solo por sí misma, sino desde su relación con la imagen y con la interactividad del medio mismo, afianzando esto desde la manera de concebir los videojuegos de Agosta. La dificultad de esto radica en la multiplicidad de partes y disciplinas con los que cada uno de estos aspectos cuenta. (ver anexo)

Jesse Schell, en The Art of Game Design: A Book of Lenses, argumenta que "las mecánicas del juego son el núcleo de lo que un juego verdaderamente es. Son las interacciones y relaciones que permanecen cuando se quita toda la estética, tecnología e historia." (2008, p. 130) Desafiaremos esta afirmación, ya que, como aporta Agosta, será necesario concebir a los videojuegos como una experiencia diseñada para el jugador, la cual cambia con cada elemento que se decida o no colocar.

Para mostrar que se recibió el input del jugador, es decir, dar feedback al respecto, es necesario recurrir ya sea a la imagen o a la música para mostrar que la acción ha tenido un efecto. Anthropy ejemplifica cómo suelen hacer los juegos para dar feedback al jugador, para hacerle saber que su acción tuvo un impacto y que está interactuando con el mundo del juego. Indica que la imagen cambia, por ejemplo, en una animación, para mostrarle esto al jugador. En contraposición, el sonido es más efectivo para mostrar feedback que la imagen, ya que puede ser un elemento que surge por encima de los otros planos que el jugador ve y oye. (Anthropy y Clark., 2014, p. 90)

Agosta también sostiene que los videojuegos se construyen desde la repetición, el contraste y la variación de sus distintas secciones. En un corte vertical en el tiempo, en cada porción veremos que el sistema se desarrolla con elementos ya presentados anteriormente, con la posibilidad de estos estar reorganizados o presentar algún cambio interno en su funcionamiento.

Partiendo de esta descripción, desarrollaremos los análisis desde la estructura formal en relación de los tres factores que nos interesan: la música, la imagen y la jugabilidad.

\section{Análisis}

Para los análisis que efectuaremos a continuación, buscamos seleccionar videojuegos que cumplan con los siguientes aspectos:

- Contengan música e imagen funcionando al mismo tiempo,

- Utilicen de manera diferente la música en relación a la jugabilidad,

- La música y la imagen respondan a input del jugador, en mayor o menor medida,

- Tengan una fuerte presencia musical. ${ }^{11}$ 
Nos alejaremos de otro tipo de características, como la época de distribución, el lugar geográfico, el género del juego, la recepción del público y el impacto relativo que cada uno tuvo, ya que no son los factores en los que hace foco este artículo. Los siguientes son, entonces, juegos en los que "se juega" con la imagen y con la música.

Agosta habla sobre los distintos pesos de la imagen y la música en relación a un videojuego. En The Art of Game Design: A Book of Lenses, Schell basa sus análisis de diseño de juegos en que el núcleo de ellos son sus mecánicas -"son las interacciones y relaciones que permanecen si quitamos todo lo estético, la tecnología y las mecánicas” (2008, p. 130). Agosta, aun tomando esta definición en cuenta, amplía su mirada hacia la experiencia del usuario, que depende en primer lugar de las decisiones de diseño que se tomen. Así, aun el más pequeño cambio alteraría lo que el diseñador quiere transmitir, y así la experiencia del jugador.12 Es esta nuestra base para buscar las relaciones desde la estructura en los siguientes análisis. Sin embargo, es necesario considerar que estos fueron realizados como pruebas de la integración de los conceptos trabajados anteriormente, y, como tales, no son ejemplo definitivo a seguir sino una base para continuar experimentando con el análisis interseccional dentro de los videojuegos.

\subsection{Patapon (2007, Pyramid)}

Patapon es un videojuego publicado en el 2007 para la consola PlayStation Portable. Combina elementos de gameplay de los juegos de ritmo, de simulación y estrategia (2017)13. Las interrelaciones entre la música y la imagen dentro de este juego son claras desde antes siquiera de que fuera publicado: a partir de una ilustración, el productor, Hiroyuki Kotani, decidió la estética del juego, y propuso hacer un juego de estrategia que incluyera tambores guerreros, con los personajes de dicha ilustración como protagonistas. (ibíd.)

Podemos argumentar, ya desde la génesis de este juego, la necesidad de la existencia de la imagen para la experiencia deseada por su diseñador. Es decir, la concepción de este juego fue hecha desde la percepción de la imagen y la música como mecánica principal -ya estaba claro cómo se iba a ver y qué tipo de juego iba a ser, y la exploración surgió desde qué es lo que podía sonar.

Como podemos ver en la imagen 1, esto tiene una correspondencia visual. El juego presenta información conocida repetitiva -el jugador reconoce la estética como propia, y sabe que estas criaturas son los personajes con los que está jugando (Anthropy y Clark, 2014, pp. 78-80). Aquí se refleja la utilización de motivos visuales claros para comunicar información al usuario, como mencionamos en la sección 1.2.

La mecánica es siempre la misma: El jugador (que toma el papel del 'dios' de estas criaturas, dentro del videojuego) se comunica con las criaturas, los patapons, mediante tambores. Para jugar, el jugador debe elegir y efectuar ciertos comandos rítmicos correctamente, para que luego las criaturas del juego lo repitan y lleven a cabo la acción que se les indica. Estos comandos serán seleccionados en relación a los aspectos visuales del juego: las pantallas muestran en imagen enemigos o situaciones adversas que el jugador deberá sortear estratégicamente. 


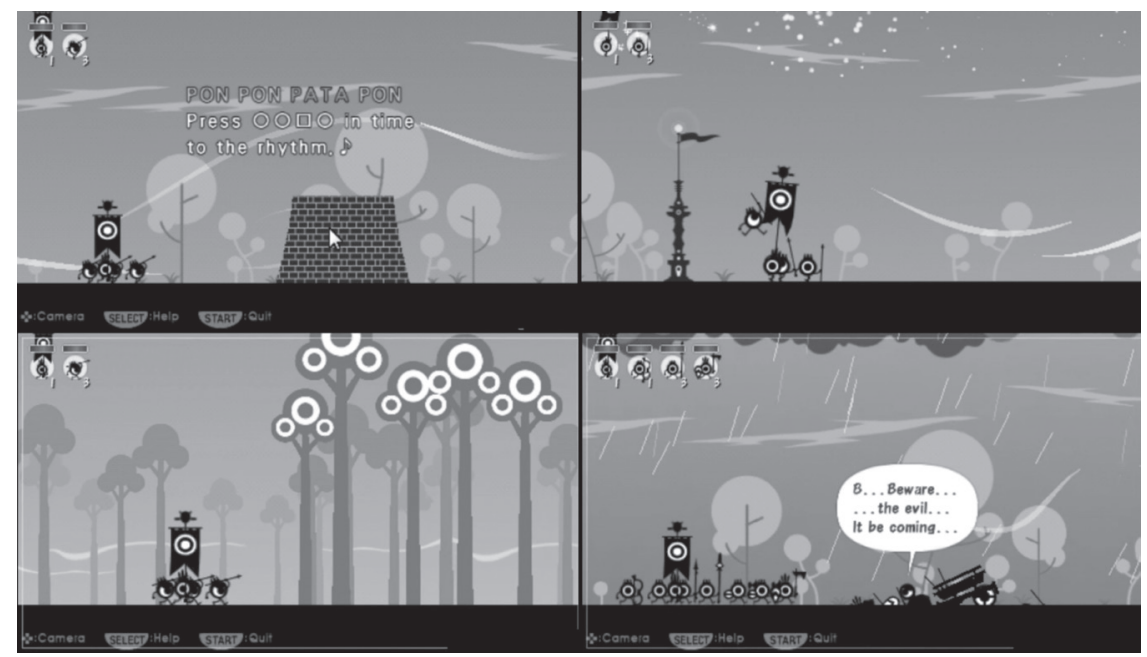

Imagen 1: Arriba: inicio y fin de la misión 2 del juego. Abajo: capturas del comienzo de las misiones 3 y 6.

El modo de juego es fácil de comprender y de aplicar rápidamente sin muchas más indicaciones. A medida que avanza, se descubren nuevos patrones que se pueden utilizar, y se presentan desafíos que requieren reacciones más rápidas o más precisas.

El juego está diseñado para que la carencia de la música no afecte a la posibilidad de jugar, o que al no poder contar con el aspecto visual del juego el feedback sonoro permita seguir jugando. Sin embargo, si desaparecieran ambos elementos, perderíamos la interfaz mediante la cual se comunica el juego con el jugador.

En respuesta a cada uno de los comandos que ingresa el jugador, las criaturas repiten sonoramente exactamente lo ingresado (o, si cometió algún error, se muestran confundidas y emiten sonidos de tono descendente, en mucha menor densidad polifónica). Esto sería el primer feedback que tiene el usuario -es decir, la indicación de que interactuó con el mundo del juego (Anthropy y Clark, 2014; Agosta, 2018). En la imagen, el juego responde con animaciones simples según el tipo de acción que estén tomando los personajes. En la imagen 1 también podemos ver que se refleja la cantidad de guerreros con los que cuenta el ejército del jugador dentro del juego. Esta cantidad, si es pequeña, también se refleja en la densidad de voces al responder a los comandos.

Todos los factores anteriores nos muestran una fuerte presencia de la música y la imagen en la experiencia del juego (Agosta, 2018). Más aún, la música es utilizada como mecánica del juego. Es discutible si el juego se puede experimentar sin ella: si bien se podrán introducir comandos, la experiencia está dada fuertemente por la música en correlación con la imagen. Hay una repetición constante en las mecánicas y en lo gráfico, además de en la música: la novedad es el reacomodamiento de los factores en cada "misión" que llevan a modificar la estrategia -y, en sí, lo que suene. 
Para analizar la posible 'ejecución' del mundo del juego para el jugador, tomaremos un solo nivel -misión, por el nombre que reciben dentro del mundo del juego-, en este caso, la misión 2. En el siguiente gráfico se representan en vertical los estratos presentes en el juego (del jugador y del mundo del juego), y en horizontal el tiempo transcurrido.

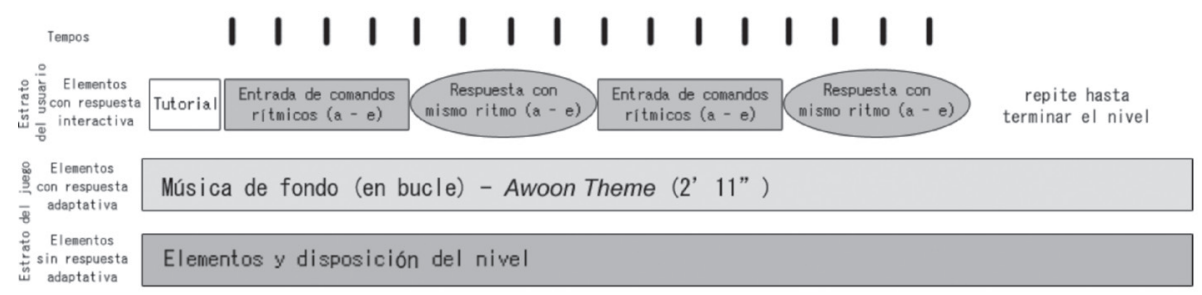

Imagen 2: Gráfico de la sucesión en el tiempo de los elementos del juego Patapon, misión 2. Autoría propia, 2018.

En el nivel superior de la imagen 2 se presentan los elementos variables en tipo y cantidad, dependientes enteramente del jugador. En este caso son las 5 posibilidades de comandos, que el jugador puede usar de la manera en la que desee. Este es el nivel mayor de variabilidad e interactividad, y de relación entre la música y la imagen. En el caso de este juego, la decisión del input rítmico -es decir, los comandos- que tome el jugador se verá reflejada exactamente en lo gráfico.

En el segundo nivel se representa la música de fondo, el soundtrack, del juego. Este no es variable sino que continuará comenzando y terminando en bucle durante el tiempo que le tome al jugador resolver la misión. Este nivel muestra la adaptabilidad como fue teorizada en sus comienzos: únicamente en el tiempo (Youngdahl, 2010, p. 34). La relación con la imagen es únicamente de contexto y textural (Jørgensen, 'What are Those Grunts..., 2007, p. 51; Anthropy y Clark, 2014, p. 98)

En el nivel inferior figuran los elementos de la misión, invariables en contenido, momento y lugar de aparición en todo el nivel. No poseen ninguna adaptabilidad en el tiempo, solo en la reacción interactiva a las acciones del jugador.

Aquí podemos ver cómo el input del jugador es el que determina el largo total de la pantalla con sus acciones (Sweet, 2015, p. 38) . Cada cuatro tempos, durante los cuales recibe a modo de feedback respuesta de parte de las criaturas del juego, el jugador puede repetir o elegir un nuevo comando. Entonces, inferimos que el juego responde adaptativamente a las acciones del jugador, y tanto la adaptación como la interactividad se reflejan visual y musicalmente. 


\subsection{Final Fantasy IX (2000, Square)}

Final Fantasy IX es un juego de rol producido y publicado por Square para la consola PlayStation. Publicado en el año 2000, tiene un foco fuerte en su historia de fantasía medieval y en sus mecánicas de batalla por turnos, típicas del género.

Siendo un juego anterior a Patapon y basándose en mecánicas en las que no intercede la música, cabría preguntarse por qué lo hemos seleccionado para su análisis. Los juegos de la saga Final Fantasy son reconocidos por su música (McCasker, 2017), y el compositor de la pieza que analizaremos, Nobuo Uematsu, ha dado numerosas entrevistas donde destaca la importancia que le da a los leitmotifs en sus obras. ${ }^{14}$

Todas las obras que musicalizan este videojuego tienen las mismas características: tienen leitmotifs reconocibles, melodías pregnantes, y continúan en bucle de principio a fin en todas las secciones del juego. La que analizaremos a continuación es Ipsen’s Heritage, pieza que aparece en un solo escenario del juego.

Esta obra es una variación del tema principal del juego, A Place to Call Home. Contiene la misma melodía y estructura que la anterior, con particularidades que veremos a continuación. El primer cambio que notaremos es la instrumentación y el timbre: se agrega percusión, la contramelodía desaparece y se suman voces masculinas en octava grave haciendo notas pedal. La melodía principal se fragmenta y pasa a estar entre las octavas 4 y 5 , cambiando nota a nota, en la parte A. En la parte B, hay un canon a dos voces. Finalmente, en todas las secciones de cadencia de cierre, se mayoriza el acorde de re final, cambiando también la melodía para explicitar la tercera mayor.
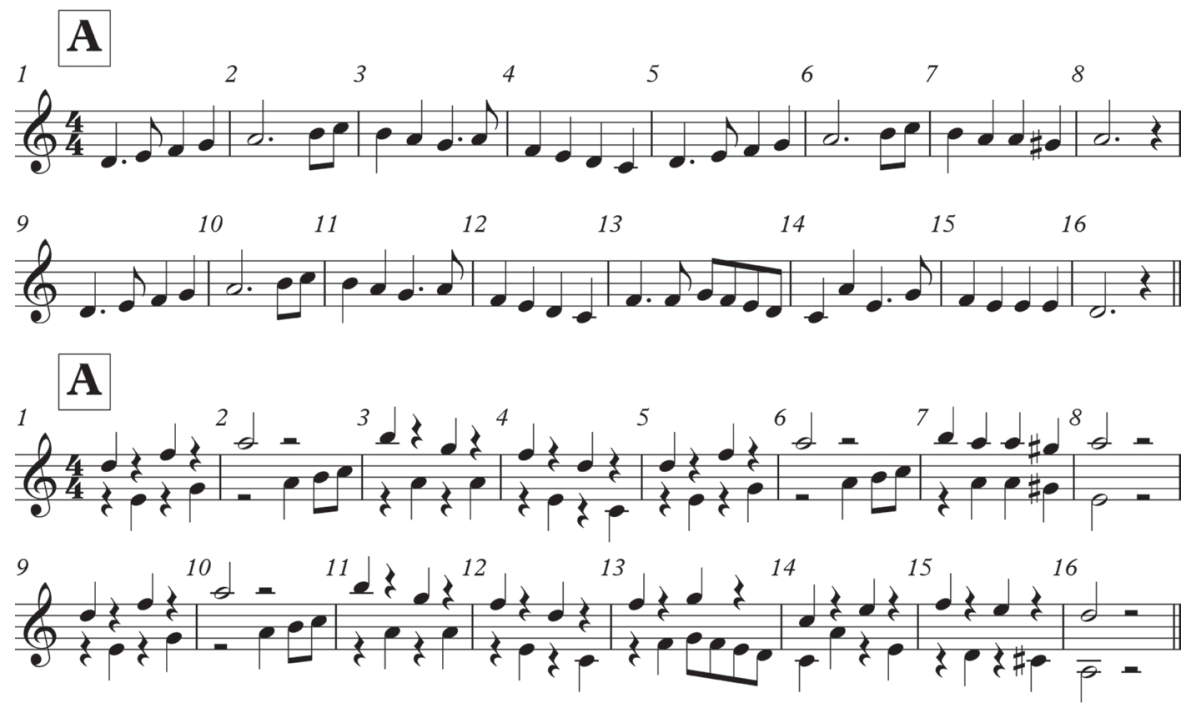

Imagen 3: Arriba: Melodía de A Place to Call Home (Nobuo Uematsu, 2000). Abajo: Melodía dividida en la parte A de Ipsen's Heritage (ibíd.). Transcripción de autoría propia, 2018. 
¿Qué es lo que nos está informando sobre el juego esta música?

La escena del juego que transcurre mientras escuchamos esta pieza es un momento particular: un castillo en donde todo está al revés. Se ven afectadas las estructuras, las imágenes, los caminos, y también parte de las mecánicas del juego. Cuando normalmente los usuarios deben buscar ataques poderosos y armas potentes, en esta sección deberán hacer todo lo contrario para poder avanzar.

Esta indicación del cambio en el modo de juego no se da verbalmente, sino que, desde el cambio en la imagen y en la música, se espera que el jugador resuelva este acertijo sin palabras. ${ }^{15}$ Con todos los aspectos ya mencionados, podemos observar una manera quizás más asemejada al tratamiento de la música en el cine (Berndt y Hartmann, 2008, p. 7): es un lugar conocido pero diferente, por lo tanto, la música es una variación de otra que el jugador ya escuchó y reconoce. Como indicamos anteriormente, la melodía cambia de octava -octava superior a inferior intercaladamente-, y el acorde menor final se vuelve explícitamente mayor con la melodía culminando en el fa\#: ambas variaciones respecto al original podrían ser maneras de representar musicalmente la 'inversión' gráfica y del modo de juego. Aquí el jugador necesita pensar 'al revés' y utilizar elementos del juego que normalmente no harían daño, objetos que ya ha dejado de usar hace muchas horas de juego, para poder infligir un daño considerable a los enemigos.

\section{Conclusiones}

"[...] el valor informativo que el sonido le añade a la imagen tiende a dar la impresión de desprenderse desde la imagen misma. Por su valor agregado, al sonido muchas veces se le da un rol menor al que merece en las películas. Esta relación problemática no existe en los juegos, sin embargo. [...] En juegos de computadora es importante examinar cómo el sonido y la imagen afectan la experiencia del juego y el juego como actividad." (Kristine Jørgensen - 2008, p. 164)

Durante nuestra primera sección, abordamos la necesidad de generar un vocabulario específico para poder tratar los temas presentes. La preocupación principal de Costikyan y Anthropy y Clark fue la de generar un vocabulario verbal para hablar sobre los elementos del diseño de los juegos y del gameplay, mientras que nosotros buscamos de qué manera referirnos a las relaciones de la música y la imagen dentro de los videojuegos, y cómo puede esto servirnos para el análisis. Enumeramos las dificultades y características del medio -las cuales a veces son las mismas-, y buscamos establecer una diferenciación con el cine respecto a la no linealidad de los videojuegos.

Es así como formulamos una red de conceptos útiles para el posicionamiento no sólo ante el análisis sino para la crítica estética de los videojuegos.

Podemos resumir lo elaborado sobre las características distintivas del medio, respecto a la música, con lo siguiente: 
Hay dos causas principales para las diferencias entre la música en los videojuegos y otros tipos de músicas. Una razón es que la música de videojuegos y su estética se desarrollaron desde un set de condiciones diferente, teniendo que lidiar con problemas técnicos y de hardware que crearon un paradigma distinto sobre cómo debería sonar esta música [...]. Otra razón es que los objetivos de crear un videojuego son muy diferentes de los objetivos de crear composiciones musicales. [...] La música de videojuegos está necesariamente particularmente apuntada hacia [comunicar desafíos, competencia, fantasía e interacción social], ya que son los fines del juego en sí mismo. En adición a esta limitación, la música en videojuegos debe seguir una estructura diferente y adaptarse a distintos factores que la música en otros espacios para que pueda caber en el juego. (Youngdahl, 2010, p. 23)

Jørgensen va aún más lejos, y en las conclusiones que se desprenden de su investigación sobre la importancia de la música en la experiencia del videojuego, elabora el siguiente concepto: el de la función transdiegética de la música.

Alterando la división tradicional entre el espacio diegético y extradiegético, la función transdiegética combina las características de usabilidad con las que apoyan el sentido de presencia en el mundo real, creando así una característica de interfaz comunicativa que le permiten al jugador acceder al mundo del juego aun manteniendo el sentido de un mundo virtual coherente (Jørgensen, 'What are Those Grunts..., 2007, pp. 176-178)

Es decir, se refiere con ello a la manera del usuario de comunicarse con el juego sin perder la inmersión en él y su mundo; al espacio virtual donde la música diegética interactúa con la no diegética por causa del jugador. Jørgensen argumenta que para los videojuegos hay sonidos que vacilan entre las categorías tradicionales de diegético y extradiegético, y que hay agentes parcialmente dentro o fuera de la diégesis. Trae a colación los siguientes como tres tipos de transdiégesis: sonidos diegéticos que no parecen tener relación natural con sus fuentes diegéticas, sonidos extradiegéticos que son relevantes para lo que sucede dentro del mundo del juego, y sonidos propios de la interfaz que funcionan de puente entre el mundo del juego y el espacio real del jugador (On transdiegetic sounds..., 2007, p. 113). De esta manera cuestiona nuestra comprensión sobre qué es diegético y qué no lo es, en comparación con los medios ficcionales lineales. Por ejemplo, la fuente del sonido de los tambores con los que el jugador se comunica con los patapons es parte del mundo del juego y de la interfaz, pero al no ser visible se dificulta su categorización. La transdiégesis flexibiliza los límites entre estas categorías tradicionales y nos es útil para analizar este tipo de situaciones. La autora también menciona la conexión emocional hacia los juegos a través de la música y la importancia de ello en la experiencia (2008, p. 171). Esto quizás sea extrapolable hacia la conexión emocional a través de las imágenes y el diseño gráfico propuestos por el juego; sería una arista interesante de explorar en un próximo trabajo.

Al mencionar que el diseño de los videojuegos pasa por la experiencia del usuario, Agosta hace hincapié en la importancia de la experiencia como un todo.

Si tomamos un juego y le quitamos su música, o la cambiamos por una diferente, el juego probablemente aún podrá jugarse, pero la experiencia final para el usuario no será la misma. Entonces, podríamos cambiar lo gráfico, o las mecánicas del juego, desdibujando 
el límite entre qué es una variación y qué es un nuevo juego. Podríamos confeccionar una escala por los distintos grados de diferenciación de la experiencia a través del intercambio de materiales. (Agosta, ver anexo) Es decir que, basados en las apreciaciones de Agosta, modificar un factor del juego equivale a modificar la experiencia. Esto demostraría la fuerte relación entre estos tres elementos.

En conclusión, parece ser difícil lograr un consenso en cómo se deben analizar los videojuegos, ya que los distintos marcos teóricos sirven a problemas particulares. Por ejemplo, Schell considera que a lo que debemos prestarle atención dentro de un videojuego es únicamente las mecánicas (2008, p. 130), mientras que Agosta sostiene que la experiencia del usuario específica es lo que hace al juego (ver anexo). No podríamos quedarnos solo con la jugabilidad como único eje desde donde desprender el análisis y la crítica. Desde lo que podemos ver en los conceptos abarcados por Jørgensen, Anthropy y Clark y Agosta, mencionados en los capítulos anteriores, los videojuegos tienden a ser considerados como un todo inseparable entre los tres ejes que tocamos en este artículo. La subjetividad de cada uno de los jugadores es también un factor importante a tener en cuenta tanto durante el diseño como durante el análisis (Majewski, 2003, p. 17).

Sin embargo, por lo visto en la sección 1.1., consideramos que a la hora de analizar música e imagen dentro del contexto, la decisión de tomar el todo como un sistema y efectuar los análisis desde esa mirada nos parece la más acertada. La música y la imagen son en cuanto responden, reflejan, reaccionan o se relacionan la una con la otra, y, por sobre todo, con la jugabilidad. (Jørgensen, 2008; Anthropy y Clark, 2014).

Con los análisis efectuados buscamos mostrar los distintos estratos que están en juego constantemente, y cómo se comportan de manera variable a lo largo del transcurso del tiempo de juego.

Si para la sección de Final Fantasy IX que analizamos durante 2.2. quisiéramos hacer un gráfico como el que realizamos en 2.1. para Patapon, nos encontraríamos con tres estratos iguales, encontrándose la única adaptabilidad de la música en su capacidad de repetirse en bucle. En Patapon el jugador informa al juego de sus decisiones y el juego muta en respuesta, mientras que en Final Fantasy IX el juego informa al jugador de manera visual y musical sobre los cambios en las reglas. Es decir, en Patapon el jugador tiene cierta influencia sobre la estructura formal del juego y su adaptabilidad, y en Final Fantasy IX el juego informa al jugador sin estar relacionado su input con la adaptabilidad estructural, más que en la duración total del juego. Esto nos lleva a pensar que no solo se vuelve necesario un tipo de análisis que incluya la jugabilidad, la música y la imagen (Jørgensen, 'What are Those Grunts..., 2007, p. 51), sino que este análisis debe mutar según el juego. Esto significaría una gran dificultad a la hora de afrontar nuevos análisis, de no ser porque no podríamos justificar que todos los videojuegos se comportarán de la misma manera que los de nuestro acotado corpus. No podría ser equivalente a establecer reglas de análisis para las películas; equivaldría, por ejemplo, a sugerir reglas iguales para todos los medios visuales. La gran variedad de modos de comportamiento -jugabilidad y mecánicas de juego- es quizás lo que delimita el marco donde serán útiles los conceptos, reglas y parámetros similares. 
En conclusión, es difícil definir qué es interno y qué externo a la diégesis, ya que tenemos elementos que pertenecen a ambas categorías o a una combinación de ellas, o bien mutan en el tiempo o pasan por fuera del límite estricto de la diégesis. Así, nos surgen nuevos interrogantes, que desafían lo que considerábamos paradigmático para el análisis de la música en los videojuegos. Al mismo tiempo, la imagen no puede pasar desapercibida, ya que el sistema del juego generalmente se conforma también desde el ámbito visual. Entonces, intensificar el foco de los análisis sobre la jugabilidad como elemento fundamental, y sobre la transdiégesis como alternativa a las categorizaciones de lo diegético y no diegético, nos puede brindar posibilidades más completas e íntegras en el campo de la investigación y las relaciones entre música y gráfica dentro de los videojuegos.

\section{Entrevista a Gonzalo Mario Agosta, game designer de Killabunnies}

(Luciana Cacik) - ¿Cuáles son los elementos más importantes dentro de un juego? ¿Podemos hacer un foco sobre la música?

(Gonzalo Agosta) - Para mí, son la mecánica del juego, la gráfica, y el sonido. Son elementos que van de la mano y forman un conjunto en todos los juegos. Seguramente haya alguna excepción, pero es la regla general.

Ya que hablamos de música, analicemos un juego en el que la música sea parte fuerte del gameplay. Por ejemplo, el Pump It $U p^{16}$. Tiene esos tres elementos que mencionamos anteriormente - la gráfica, el gameplay, la música -y los sonidos-. Es un juego de ritmo donde debés pulsar, con los pies, el botón indicado. Se identifican patrones y el jugador los va copiando. La música, el ritmo, es un elemento fuerte en la mecánica, ya que con el ritmo vienen los patrones que se deben pulsar. Además, obviamente, vemos los gráficos en la pantalla que refuerzan esta idea. Podemos ver que aquí estamos desplazando un poco los gráficos, pero tiene que ver con cómo cada desarrollador usa cada recurso. De todos modos, este juego va relacionando cada paso que tenemos que ir dando -lo que se debe pulsar- con una flecha y un color. Aun si parece que la gráfica es lo de menos, para el jugador así es más rápido relacionar un color y la posición constante en donde está la flecha con la acción que se debe tomar.

LC - El Pump It Up es un buen ejemplo, ya que es un juego en el que podemos quitar del todo la música y seguir "jugando" de alguna manera. Pero, de hacer esto, ¿se perdería el valor del juego?

GA - Más que el valor, se pierde algo importante de estas tres cosas que estamos hablando, que es la experiencia del juego. Si se quitara la música (y/o los efectos de sonido, los cuales dan feedback) cambia la experiencia con la que fue diseñado.

LC - Muchas investigaciones sobre los videojuegos comienzan comparándolos con el cine ¿Te parece éste y los videojuegos tienen una relación muy cercana?

GA - No creo que ninguna respuesta sea tan estricta como "si" o "no". Hay juegos que se acercan mucho a lo cinematográfico, como The Last of Us, que tiene mucho contenido en animaciones y secuencias sin jugabilidad. Incluso la duración de todas esas escenas juntas equivalen a más tiempo que largo normal de una película. Hay juegos con mucha menos interacción con el jugador. 
LC - Hablando puntualmente del game design, ¿̇lo pensás siempre desde la experiencia del usuario?

GA - Personalmente, siempre pienso en cómo van a cuadrar estas tres cosas [música, imagen y gameplay] con lo que estoy buscando transmitir.

Otro juego muy exitoso del que podemos hablar es el Final Fantasy VII. Una de las características del compositor era que armaba temas, leitmotifs, para cada personaje. Podría haber sido un juego para la generación anterior de plataformas, pero la experiencia, siendo $3 \mathrm{D}$, con la música tan cuidada, entre otras cosas, transmitía, desde la historia, escenas sumamente emotivas, ancladas fuertemente en la música. Toda la música está compuesta en midi y el tema del final del juego incluye por primera vez voces digitalizadas. Está buscando un clima en la batalla final que el resto del juego no tiene. ${ }^{17}$

En los juegos de la saga Final Fantasy hay mucho que analizar dentro de lo que es arte. En esa discusión eterna sobre si un juego es una obra de arte o no, un cuadro por ser un cuadro no es una obra de arte, es un cuadro, y quizás está bien que sea un cuadro. Hay videojuegos que son pasatiempos y está bien que sean pasatiempos, y hay juegos que se pueden analizar como que tienen mucho trabajo, porque son un conjunto de muchas disciplinas artísticas. Es difícil de encasillar y los rubros son generales. Depende de las categorías de análisis que le sirvan a cada uno. Hay muchas formas de analizar en el diseño del juego hasta dónde 'invaden' el sonido y la música dando feedback, indicando qué se hizo bien o qué mal; hay otros que lo aplican directamente en su mecánica de juego (por ejemplo, juegos de ritmo, como la Crypt of the NecroDancer).

LC - Si uno cambia la mecánica, el juego cambia mucho, pero parecería que cambiando la imagen o la música, el juego no cambia demasiado. ¿Cómo pensás esto?

GA - La mecánica de juego probablemente no cambiaría, pero igual te está transmitiendo otra cosa. La experiencia de juego cambia aun cuando la mecánica es la misma. El todo tiene una correlación.

LC - Para generar el nivel correcto de dificultad - suficiente información nueva como para ser divertido, y no demasiada como para no agobiar. ¿Cómo lo pensás, al momento de crear niveles?

GA - Depende, primero, del tipo de juego, y el usuario al que se lo está destinando, obviamente. Y dentro de lo fácil y lo difícil, dónde queremos que esté el juego. Eso sería parte del scope, de adónde tengo que apuntar. Es mucho generar con los elementos anteriores y probar.

Hablando de un juego hipotético que tiene pantallas en las que te movés, que tiene enemigos, patrones o puzzles, todos elementos del juego. Primero se los va presentando de a poco, que el usuario aprenda a usar de a uno, y luego, por ejemplo, se puede ir combinando elementos que antes no se habían usado juntos. Es un trabajo muy manual sobre qué elementos pueden ir juntos o no.

LC - Entonces, ¿podríamos decir que tenés un sistema y dentro de él tenés una serie de cosas que ubicás según la necesidad del juego y del nivel?

GA - Sí. Es flexible, pero por lo menos yo trabajo así. Pienso en curvas de dificultad y cómo irlas modificando y ajustando, para ir conduciendo al jugador. Hay un dicho que dice que la primera pantalla es la última que hacés, porque tiene que ir conduciendo los 
elementos y las dificultades. Es mucho testing. Un trabajo coordinado entre el game designer, los miembros del equipo y testers exteriores.

LC - ¿Cómo se traslada el concepto de adaptabilidad de la música al resto de los elementos de los videojuegos?

GA - Directamente estaría implícito. Cuando un personaje come una fruta, escuchamos un sonido y vemos una imagen que cambia.

LC - ¿Alguna vez indicaste una mecánica desde la música?

GA - Creo que no, porque es más fácil reparar en lo que es la imagen. Quizás en un juego con gráficos minimalistas con más preeminencia del sonido sí es aplicable, pero probablemente hay cosas más fáciles de comunicarlas de otra manera. Además, hay muchos jugadores que directamente le quitan la música o el sonido al juego, y es difícil asegurarse de que los jueguen con música. Pero si un proyecto lo amerita, se aplica.

LC - Pensás, entonces, en la forma del juego en general.

GA - Sí. No solo en agregar elementos nuevos, sino en combinar con otros elementos que ya existían o expandirlos. Si comparamos con un cancionero, las progresiones de acordes son muy similares siempre, son siempre los mismos acordes, pero si el intérprete [el game designer] sabe jugar con los timbres, con los agregados, con arpegios, etcétera, va a poder comunicar esos climas y quiebres. Es similar con los videojuegos.

\section{Notas}

1. A Game Design Vocabulary es un libro dividido en dos partes: la primera es la postura de Anthropy y la segunda de Clark. Siempre que citemos este libro, mencionaremos a cuál de las autoras nos estamos refiriendo.

2. Si bien en el comienzo de los videojuegos tanto la música como la imagen no presentaban una preeminencia tan importante como en el cine, la evolución del medio fue tanto paralela al cine como retroalimentada por él, lo cual lleva a que, según algunos autores, en la actualidad (y haciendo salvedades dependiendo de los distintos géneros) sigan paradigmas similares de composición de la imagen y la música o narrativa. Marks, 2009: xix; Sweet, 2015: 17.

3. Ver Sweet, 2015: 36.

4. "A videogame is a game which we play thanks to an audiovisual apparatus and which can be based on a story." Hemos obviado la segunda parte de la definición, ya que la existencia o no de una historia no es pertinente para los presentes análisis y posteriores conclusiones.

5. Contraponer con Anthropy, quien habla del discurso exclusivamente desde el vocabulario y la manera de comunicar ideas verbalmente. (2014: 9)

6. "The aesthetics of a game is created by tension / resolution cycles, where the resolution of a cycle are [sic] felt by the player as some consequence of his choices." Traducción propia.

7. A lo largo de este artículo se utilizará el término en español “jugabilidad”, si bien puede ser más común la palabra en inglés.

8. Los autores utilizan la palabra playability; si bien gameplay se traduce también como 
“jugabilidad” cabe aclarar que gameplay y playability no son términos intercambiables.

9. Citados de su Manifiesto del Contrapunto Sonoro, 1928.

10. Ver anexo: Entrevista a Gonzalo Mario Agosta cedida para este artículo.

11. Esto podría ser un aspecto subjetivo; más allá de la importancia de la conexión emocional en la música de los videojuegos (ver Jørgensen, 2008), hemos seleccionado ejemplos de juegos que han sido reconocidos por su aspecto musical.

12. Recordamos también lo trabajado en secciones anteriores: la experiencia del jugador es también propia a cada uno y sus experiencias. (Eco, 1962: 32; Schell, 2008: 97; Sweet, 2015: 37) 13.En https://blog.eu.playstation.com/2017/08/01/the-complete-story-behind-rhythmaction-classic-patapon-as-told-by-the-games-creators/ . Consultado el 1/10/2018.

14. Entrevista a Nobuo Uematsu por Weekly Famitsu. Recuperada de https://www.webcitation.org/6EDcYWTVk?url=http://www.nobuouematsu.com/nobrpg.html el 1/11/2018. 15. Aun si el jugador no respetara esta nueva regla, podrá seguir jugando y avanzando, pero con mucha más dificultad. Así, el no poder resolver el desafío no es impedimento para que continúe el juego.

16. Juego de ritmo de tipo arcade -es decir, para salones de videojuegos-, en donde se debe pulsar con los pies las flechas indicadas al ritmo de la música, simulando un baile.

17. A pesar de que las capacidades de la consola ya permitían música con calidad de $\mathrm{CD}$, el compositor, Uematsu, optó usar sonidos MIDI. El tema que menciona Agosta es One-Winged Angel, una composición sinfónico-coral que suena en el clímax del juego. El texto, cantado enteramente por voces digitalizadas, es extraído de parte del manuscrito Carmina Burana.

\section{Listas de Referencias bibliográficas}

Anthropy, A., Clark, N. (2014). A Game Design Vocabulary, Indiana, Estados Unidos: Addison-Wesley.

Berndt, A., Hartmann, K. (2008). The Functions of Music in Interactive Media, Erfurt, Alemania: Springer.

Costikyan, G. (1994). I Have No Words \& I Must Design: Toward a Critical Vocabulary for Games. En Frans Mäyrä (Ed.), Computer Games and Digital Cultures Conference 2002. Conferencia llevada a cabo en Tampere, Finlandia.

Coxon, S. (trad.) (s.f.). Interview by Weekly Famitsu [entrevista a Nobuo Uematsu por Weekly Famitsu]. Recuperado de https://www.webcitation.org/6EDcYWTVk?url= http://www. nobuouematsu.com/nobrpg.html.

Eco, U. (1992). Obra abierta, (Roser Berdagué, trad.) Barcelona, España: Planeta-Agostini (Obra original publicada en 1962).

Esposito, N. (2005). A Short and Simple Definition of What a Videogame Is. En S. Castell y J. Jenson (Presidencia), DiGRA 2005 Conference: Changing Views - Worlds in Play. Conferencia llevada a cabo en Vancouver, Canadá.

Glancey, P. (1996). The Complete History of Computer and Video Games, Reino Unido: EMAP.

González Sánchez, J. L., Padilla Zea, N., Gutiérrez Vela, F. L., (2010). From Usability to Playability: Introduction to Player-Centred Video Game Development Process, San Diego, CA, Estados Unidos: HCI International. 
Grove, G., Sadie, S. (2001). The New Grove Dictionary of Music and Musicians, Oxford, Inglaterra: Oxford University Press.

High, A. (2012). Is Game Music All It Can Be? Recuperado de http://www.gamasutra.com/ view/feature/181003/is_game_music_all_it_can_be.php.

Hunicke, R., Leblanc, M., Zubek, R. (2004). MDA: A Formal Approach to Game Design and Game Research. Recuperado de https://www.cs.northwestern.edu/ hunicke/MDA.pdf.

Jørgensen, K. (2007). On transdiegetic sounds in computer games. Northern Lights: Film and Media Studies Yearbook, volumen 5, n I, pp. 105-117, Bristol, Reino Unido: Intellect Press.

Jørgensen, K. (2007). 'What are Those Grunts and Growls Over There?' (tesis doctoral). Copenhagen University, Copenhague, Dinamarca.

Jørgensen, K. (2008). Left in the dark: playing computer games with the sound turned off. En K. Collins (Ed.), From Pac-Man to Pop Music: Interactive Audio in Games and New Media (pp. 163-176). Ontario, Canadá: Ashgate.

Majewski, J. (2003). Theorising Video Game Narrative (tesis de grado). Bond University, Queensland, Australia.

Marks, A. (2009). The complete guide to game audio, Oxford, Inglaterra: Elsevier.

McCasker, T. (12 de julio de 2017). 30 years of Final Fantasy: a cult of devotion, and the music still soars. The Guardian. Recuperado de https://www.theguardian. com/technology/2017/jul/13/30-years-of-final-fantasy-a-cult-of-devotion-and-the-music-still-soars.

Natkin, S. (2010). Interactivity in Games: The Player's Engagement, Brisbane, Australia: Springer.

Rollings, A., Adams, E. (2003). On Game Design, San Francisco, CA, Estados Unidos: New Riders Publishing.

Rose, G. (2001). Visual Methodologies: An Introduction to the Interpretation of Visual Materials, Londres, Inglaterra: SAGE Publications.

Schell, J. (2008). The Art of Game Design: A Book of Lenses, Burlington, Estados Unidos: Elsevier.

Sweet, M. (2015). Writing interactive music for videogames: a composer's guide, New Jersey, Estados Unidos: Addison-Wesley.

Thompson, J. C., Ouellette, M. A. (2014). The Game Culture Reader, Newcastle, Inglaterra: Cambridge Scholars Publishing.

Youngdahl, E. (2010). Play Us a Song: The Structure and Aesthetics of Music in Video Games (tesis de grado). Wesleyan University, Connecticut, Estados Unidos.

Zdyrko, D. (s.f.). Interview by PSX IGN [entrevista a Nobuo Uematsu por PSX IGN]. Recuperado de https://www.webcitation.org/6EDcYjnXh?url=http://www.nobuo uematsu. com/round.html.

\begin{abstract}
The creation of a specific vocabulary for video games and game design analysis poses a challenge shared by the analysis of the correlation between image and music in them. Concepts from filmmaking, graphic design and other media alone would be insufficient; the interactivity and non linear nature of the video game medium are both their main methodologic issue and distinctive characteristics. In this article we'll try to link mu-
\end{abstract}


sic, image and their means of communication between them and with the player, from the gameplay and playability perspective.

Key words: image - music - playability - game design - adaptability - modularity

Resumo: A geração de um vocabulário específico para o análise dos videogames e o game design é uma dificuldade da qual também não escapa o análise da relação imagem-música dentro deles. Os conceitos extraídos do cinema, do desenho gráfico, ou de outros medios lineaís seriam insuficientes para afrontar isto; a interatividade e no linealidade do médio são tanto a su principale dificuldade metodológica quanto as suas características distintivas. Neste artigo tentaremos vincular a imagem e a música e as suas maneiras de se comunicar entre elas e com o jogador, desde a jogabilidade mesma.

Palavras-chave: imagem - música - jogabilidade - game design - adaptabilidade - modularidade

[Las traducciones de los abstracts fueron supervisadas por el autor de cada artículo] 